\title{
PSYCHOSOCIAL CORRELATES OF POST-TRAUMATIC STRESS DISORDER IN PATIENTS WITH FIRE BURNS
}

\section{Afsheen Masood', Fatima Kamran ${ }^{1 \otimes}$, Rafia Rafiq'}

\section{ABSTRACT}

OBJECTIVE: To elucidate the psychosocial correlates of post-traumatic stress disorder (PTSD) in the burn victims of Pakistan.

METHODS: A total of 200 burn victims were included in the sample. The standardized measures were used to assess the symptom levels of PTSD. The detailed demographic profile of the patients was also received for gleaning the demographics' association with PTSD symptoms. The screening of PTSD symptoms for further clinical management had also been catered through this data collection strategy. For analysis SPSS version 22.0 was employed.

RESULTS: Mean age of the respondents was $30.56 \pm 10.3$ years. Most of the respondents were males $(n=1 \mid I, 55.5 \%)$, panjabi speaking $(n=120 ; 60 \%)$, followers of Islam $(n=146 ; 73 \%)$, lower socioeconomic class $(n=93 ; 45.5 \%)$, illiterate $(n=1 \mid 4 ; 57 \%)$, unemployed/housewife $(n=155 ; 77.5 \%)$ and were married $(n=143 ; 71.5 \%)$. Most of the respondents had high PTSD levels $(n=169 ; 84.5 \%)$. Panjabi natives $(n=105 / 120 ; 87.5 \%)$, married persons $(n=120 / 143)$, urban background $(n=1|10 / 1| 8 ; 93.2 \%)$, persons currently living with children $(n=102 / 123 ; 82.9 \%)$, unemployed/housewife $(n=140 / 155$; $90.3 \%)$, illiterate $(n=109 / 114 ; 95.6 \%)$, respondents who experienced domestic violence $(n=|50 / 15| ; 99.3 \%)$ and those experienced burn injuries less than one-year duration $(n=\mid 40 / 151 ; 92.7 \%)$ had higher PTSD levels than their counterparts. Fifty-one $(25.5 \%)$ respondents had suicidal ideation.

CONCLUSION: Being male, married, illiterate, urban background, having history of domestic abuse, unemployed/housewives, having lower education level and experienced burn injuries less than one-year duration are significant psychosocial correlates of PTSD in patients with fire burns.

KEY WORDS: Stress Disorders, Post-Traumatic (PTSD) (MeSH); Stress Disorder (MeSH); Burns (MeSH); Psychosocial factors (non-MeSH).

THIS ARTICLE MAY BE CITED AS: Masood A, Kamran F, Rafiq R. Psychosocial correlates of post-traumatic stress disorder in patients with fire burns. Khyber Med Univ J 2018;10(1):8-13.

\section{INTRODUCTION}

$B^{u}$ urn injuries are a major cause of morbidity and mortality throughout the world. According to World Health Organization, burns are responsible for 265,000 deaths worldwide each year. Approximately $(486,000)$ cases of burns are treated annually in the United States alone.' Literature shows that most burn injuries are accidental and are associated with cooking. ${ }^{2,3}$ In addition to accidental fire burns, burns by assault are also very common, especially in South Asia. One such example was reported in newspaper dated August 28, 2015, an assault based attack on daughter by father and his uncle wherein a father burnt alive his daughter on suspicion and doubt of adultery in Vehari. ${ }^{4}$ After fire burns, the assault-based acid throwing or vitriolage is more common in this region than anywhere else. ${ }^{5}$ According to an indigenously conducted research in Pakistan, $46 \%$ of burns in Pakistani women were due to bursting of stoves or women put to fire after throwing petrol inside their homes while 33\% were intentional, caused by the
\ Institute of Applied Psychology, University of the Punjab, Lahore, Pakistan

Email:drafsheenmasood@gmail.com

Date Submitted: March I, 2017

Date Revised: January 17, 2018

Date Accepted: January 21,2018

women's own close relatives and the leading cause reported were household quarrels. ${ }^{6}$ Progressive Women Association, a nongovernmental organization working in rehabilitation sector of burn patients has documented 8,000 cases of women who were deliberately burnt, scalded or subjected to acid attacks in the Islamabad area from 1994 to $2010 .^{7}$ Thus, in South Asia, burn injuries establish itself as a major social dilemma thus reprimanding the grave attention from researchers as well as policy makers.

Burn injuries result in severe physical disabilities due to complications like scarring and contractures. ${ }^{8}$ The psychosocial consequences of fire burns are not less debilitating as disfiguringscars from burns may lead to wide array of behavioral and psychological complications. These complications may involve so varied such as social rejection, loss of self-esteem, stress, anxiety, depression and frustration. All this cumulatively gets expressed in PostTraumatic Stress Disorder (PSTD) related symptoms after few months of recovery. There might have been other dimensions of this loss such as financial difficulties and protracted hospital stay leading to poorer socialization patterns. ${ }^{10-13}$ Van reported alarmingly higher prevalence of PTSD related symptoms in patients with fire burns. ${ }^{13}$ Though some empirical evidences have revealed that few other significant issues also prevail such as sleep problems, states of partial confusions, Generalized Anxiety Disorder and lower physical and social functioning. 13,14

In the mid-nineteenth century, Jacob Mendes da Costa, an American surgeon, described a syndrome (da Costa syndrome) consisting of palpitation, dyspnea, extreme fatigue and faintness among soldiers of American civil war (186I-1865) who were exposed to excessive stress and fear. Life-threatening stressful events leave lasting scars on an individual's personality and behavior. After Costa's 
discovery of this syndrome, more than 150 years of research has elapsed and after several modifications in terminology, today, the psychological morbidity following a traumatic life event is embodied in another term: PTSD. Initially this was termed as form of anxiety disorder but due to its own distinctive features, in most recent revision, this has been classified as distinctively separate disorder with its own specific symptoms specificities. According to Diagnostic and Statistical Manual-5, PTSD follows exposure to a traumatic life event and is characterized by recurring, involuntary and intrusive memories of the event in the form of flashbacks and dreams; avoidance of or efforts to avoid stimuli related to the event and increased arousal and reactivity in response to the event. 16,17 $^{17}$

This has been reported in western empirical findings that a lifetime PTSD prevalence of $8.3 \%$ in general population of USA exists while some other researches revealed that a full
PTSD prevalence of $1.8 \%$ and a partial PTSD prevalence of $8.7 \%$ in the general population of Germany is reported. ${ }^{18-20}$ Loey, et al. reported a PTSD prevalence $13-45 \%$ among burn victims while Sadeghi-Bazargani, et al. found that $31.5 \%$ of the burn victims in their study in Iran had a positive PTSD screening test after 3 months of injury. ${ }^{19-21}$ From the above mentioned estimates of PTSD prevalence, it is clear that while burn patients are at a greater risk of developing PTSD than general population, though not all of them go on to develop PTSD. A review of literature shows that several factors, both subjective and objective, predict the development of PTSD in patients of burn injuries. ${ }^{22}$ Prominent among these factors are low coping self-efficacy, ineffective coping behaviors, immature defense styles, female gender, burns involving hands, higher percentage of total body surface area burnt, younger age, low social functioning, high neuroticism and low social support. ${ }^{23-25}$
In addition to the above factors, a recent study in China found that PTSD levels were associated with demographic features and bio psychosocial factors. ${ }^{26}$

Numerous researches have been conducted in the west that have expounded over the predictors of PTSD but somehow indigenous Pakistani empirical researches on this phenomenon is scarce. Pakistanis are confronting different challenges as far the psychosocial effects of such catastrophe are concerned. Most of the predictors of PTSD seem to have their fueling from the contextual factors which have been identified as causing the stigmas in the society. Contemplating on this contextual perspective phenomenon, a study selectively focused on greater percentage of body surface area burnt to be the most significant factor in determining the risk of PTSD since appearances and looks are cherished much more than fewer decades back. ${ }^{27}$ Given the paucity of empirical studies in our country about

TABLE: I PARTICIPANT'S CHARACTERISTICS $(n=200)$

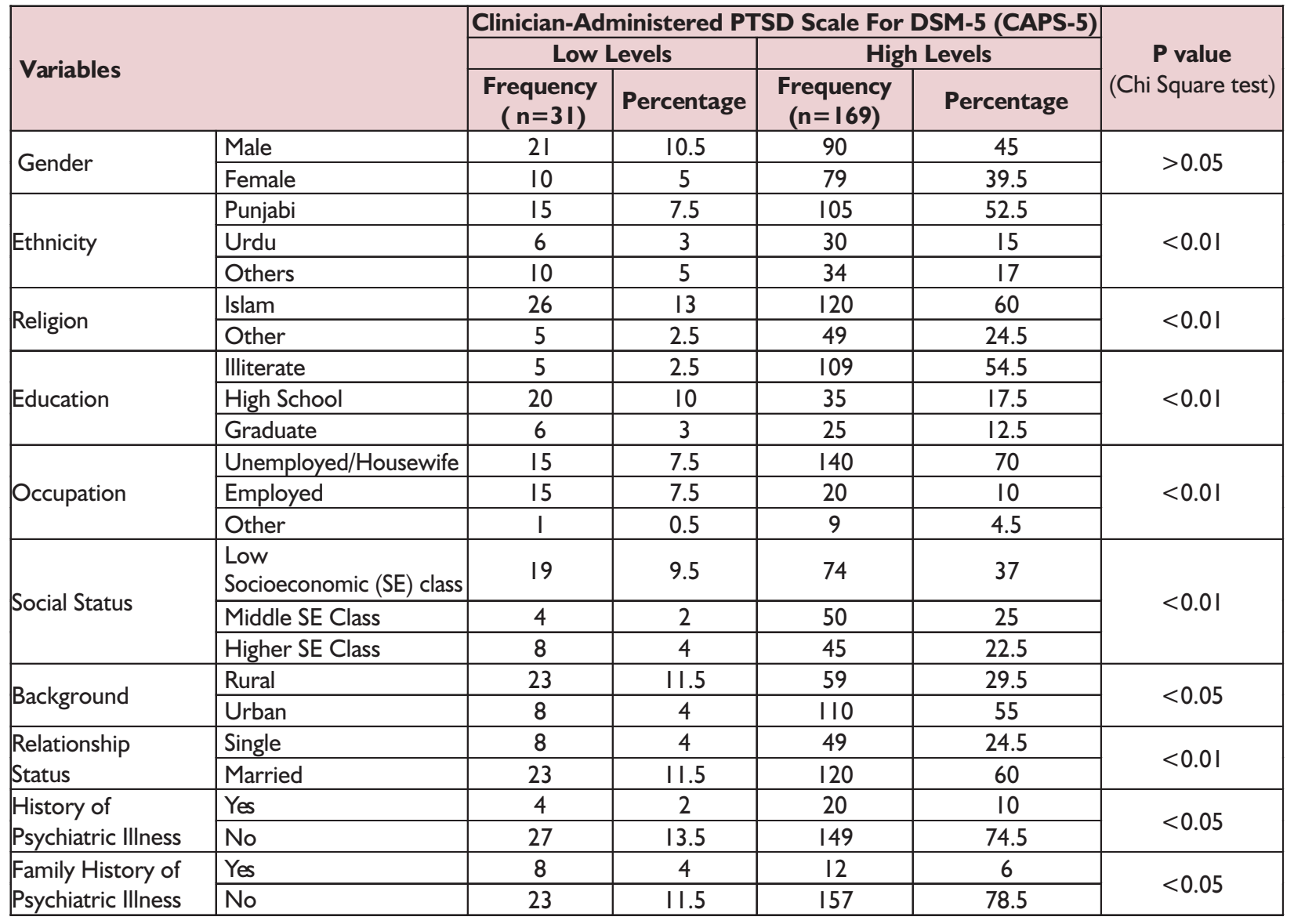


TABLE II: PSYCHOSOCIAL CORRELATES OF PTSD IN BURNT PATIENTS $(\mathbf{N}=\mathbf{2 0 0})$

\begin{tabular}{|c|c|c|c|c|c|c|}
\hline \multirow{3}{*}{ Variables } & & \multicolumn{4}{|c|}{ Clinician-Administered PTSD Scale For DSM-5 (Caps-5) } & \multirow{3}{*}{$\begin{array}{c}\text { P value } \\
\text { (Chi Square test) }\end{array}$} \\
\hline & & \multicolumn{2}{|c|}{ Low Levels } & \multicolumn{2}{|c|}{ High Levels } & \\
\hline & & $\begin{array}{c}\text { Frequency } \\
(n=3 I)\end{array}$ & Percentage & $\begin{array}{c}\text { Frequency } \\
(n=169)\end{array}$ & Percentage & \\
\hline \multirow{2}{*}{\begin{tabular}{|l|} 
Domestic \\
Violence \\
\end{tabular}} & Yes & $\mathrm{I}$ & 0.5 & 150 & 75 & \multirow{2}{*}{$<0.01$} \\
\hline & No & 30 & 15 & 19 & 9.5 & \\
\hline \multirow{2}{*}{\begin{tabular}{|l|} 
Forensic \\
History
\end{tabular}} & By Accident & 24 & 12 & 65 & 32.5 & \multirow{2}{*}{$<0.05$} \\
\hline & By Assault & 7 & 3.5 & 104 & 52 & \\
\hline \multirow{2}{*}{$\begin{array}{l}\text { Time Since } \\
\text { Burn }\end{array}$} & I Year & 11 & 5.5 & 140 & 70 & \multirow{2}{*}{$<0.01$} \\
\hline & $>\mid$ year & 20 & 10 & 29 & 14.5 & \\
\hline \multirow{2}{*}{\begin{tabular}{|l|} 
Permanent \\
Disability
\end{tabular}} & Yes & 9 & 4.5 & 41 & 20.5 & \multirow{2}{*}{$<0.05$} \\
\hline & No & 22 & 11 & 128 & 64 & \\
\hline \multirow{2}{*}{ Burnt Face } & Yes & 24 & 12 & 79 & 39.5 & \multirow{2}{*}{$>0.05$} \\
\hline & No & 7 & 3.5 & 90 & 45 & \\
\hline \multirow{2}{*}{ Living With Children } & Yes & 21 & 10.5 & 102 & 51 & \multirow{2}{*}{$<0.01$} \\
\hline & No & 10 & 5 & 67 & 33.5 & \\
\hline \multirow{2}{*}{ Suicidal Ideation } & Yes & 2 & $\mathrm{I}$ & 49 & 24.5 & \multirow{2}{*}{$<0.01$} \\
\hline & No & 29 & 14.5 & 120 & 60 & \\
\hline
\end{tabular}

the plausible factors predisposing the patients with burns towards PTSD, further investigation is required.

Thus the main goal of this research study was to fill this gap in literature and it has also been designed with the aim to determine the demographic and psychosocial factors associated with PTSD in patients with fire burn injuries in Pakistan. Another aim was to explore the prevalence of PTSD in fire burn victims seeking medical support at teaching hospitals in Lahore and Rawalpindi, Pakistan. The insightful contribution of the findings can be pragmatically be used in devising intervention programs of counseling and psychotherapies for effective rehabilitation of patients with fire burns

\section{METHODS}

This quantitative study was designed through cross-sectional survey research design. The sample size was computed through systematic and standardized formula used for computing minimum sample size. Minimum sample size required for the present study came out to be 170 using following parameters: margin of error (5\%), confidence level $(90 \%)$ and response distribution (50\%). Since, there were no a-priori estimates of prevalence of PTSD among patients with burn injury in Lahore and Rawalpindi, in this research study a hypothetical population size of 20,000 was used. There has been little variation in sample size for populations more than 20,000 (Raosoft, sample size calculator). Assuming the minimal required sample to be 170 , a bit more than minimal strength was obtained in order to fulfill the requirement.

The respondents were recruited through non probability purposive sampling procedures by hospital administration according to predetermined criterion of research of including only those with fire burns. A total of 200 respondents, age ranges between 20-55 years were referred to a clinical psychologist through outpatient department as most of the patients with fire burns sought follow up and cosmetic surgery after few months of recovering from fire burn injuries. Thus the patients comprised mainly of enrolled clients at burn centers and plastic surgery units of Mayo Hospital, Services Hospital and Jinnah Hospital, Lahore and two private Cosmetic Centers for rehabilitations became the targeted sample set. The data collection lasted for four months from Nov, 2015 to Feb, 2016. The patients seeking follow-up and checkups were included in this study. The instrument used included the demographic information sheet and Clinician-Administered PTSD Scale for DSM-5 (CAPS-5). After seeking formal permissions from all concerned departments, the respondents were made to give their consent on written Performa before their active participation in the study. All the participants were ensured confidentiality, anonymity and right to withdraw. The Clinician-Administered PTSD Scale for DSM-5 (CAPS-5) is a 30item structured interview that corresponds to the DSM- 5 criteria for PTSD and formal online training was received before administering this to target respondents. The demographic section included information on variable such as age, ethnicity, background, family structure, occupation, relationship and socioeconomic status. The data were analyzed in SPSS v. 22.00 (IBM, Chicago, Illinois). Descriptive statistics and frequencies were run for categorical variables. Mean (SD) was calculated for quantitative variables. Pearson Product Moment Correlation was employed. Chi Square test was used to check association between independent categorical variables with at least 5 expected values in each cell.

\section{RESULTS}

A total of 200 respondents were evaluated. Mean scores on age and PTSD revealed that mean age of the respondents was $30.56 \pm 10.3$ years. Most of the respondents were males $(\mathrm{n}=\mathrm{II} \mathrm{I}, 55.5 \%)$, panjabi speaking $(n=120 ; 60 \%)$, followers of Islam $(n=146 ; 73 \%)$, lower socioeconomic class $(n=93 ; 45.5 \%)$, illiterate $(n=1 \mid 4$; $57 \%)$ and were married $(n=143$; 
7I,5\%). Most of the respondents $(n=169 ; 84.5 \%)$ had high PTSD levels (Table I). A small percentage of the respondents had received psychological therapy in the past, cosmetic treatments and group therapy. Among men, a fewer of the respondents were heavy smokers and abused drugs such as antidepressants, sleeping pills, gutka and heroin. Fifty-one (25.5\%) respondents had suicidal ideation.

Panjabi natives ( $n=105 / 120 ; 87.5 \%)$, married persons $(n=|20 /| 43)$, urban background ( $n=110 / 118 ; 93.2 \%)$, persons currently living with children $(\mathrm{n}=102 / 123$; $82.9 \%)$, unemployed/housewife $(n=140 / 155$; $90.3 \%)$, illiterate $(n=109 / 114 ; 95.6 \%)$, respondents who experienced domestic violence $(n=\mid 50 / 151$; $99.3 \%)$ and those experienced burn injuries less than one-year duration $(n=|40 /| 5 \mid$; 92.7\%) had higher PTSD levels than their counterparts. Various psychosocial correlates of PTSD in burnt patients are given in Table II.

\section{DISCUSSION}

Results revealed that level of PTSD is more in Punjabi ethnic group (fire burn victims), in comparison to any other ethnic group, this is attributable to their prime place of location, from where mainly the respondents were accessed. Married females with no psychiatric premorbid history, reported higher scores on PTSD related symptoms. Hundreds of women are disfigured or die of stove-burns every year. Studies suggested that the victims are usually young married women and the aggressors include husbands and inlaws. ${ }^{6,7}$ The motive behind stove burning is to get rid of the lady in home and get married with new one without any raised social queries and objections, sometimes women are burnt in order to kill them by apparently accidental mode and that paves the way for remarrying thus claiming more dowries or have an heir for the family. This empirical study showed that among burn patients unmarried victims were $61.1 \%$, married were $1 \mathrm{I} .1 \%$ and divorced were $27.8 \%$. The percentage of illiterate people was $22.2 \%, 44.4 \%$ were under matriculation and $33.3 \%$ were above matriculation. $44.4 \%$ of the victims were related to beautician by occupation, $5.6 \%$ were housewives and $50 \%$ were related to other occupations or were idle. $61.1 \%$ of the victims were having 10,000 monthly income and $38.9 \%$ having 10,000 of monthly income. $77.8 \%$ were from joint family system and $22.2 \%$ from nuclear family system. $^{32}$

This research study revealed that a higher prevalence of PTSD is evident in patients with fire burns. Studies have generally reported lower PTSD levels in victims of burn injuries. For instance, an empirical finding reported a PTSD prevalence of $38.1 \%$ in a Turkish population of burn victim. ${ }^{7}$ It was reported in Iran that prevalence of $31.5 \%$ in an Irani population. However, a study from our country showed that $77 \%$ of the patients with acute burn injury were at risk of developing PTSD which is close to our estimate. ${ }^{21}$ The higher prevalence of PTSD in burn victims of our country may be attributed to the low number of mental health facilities in our country. According to a WHO survey only 5 mental hospitals and 342 psychiatrists exist in Pakistan to cater to the needs of more than 160 million people (WHO-AIMS Report on Mental Health System in Pakistan, 2009). Worsening this situation is the stigmatization by the society of the mental patients, an attitude which discourages people from seeking psychological treatment. The high levels of PTSD in our study sample are, thus, expected given the reluctance of patients to avail the already meager psychiatric facilities. Higher educational attainment (university degree) was associated with lower PTSD level. Although we couldn't find any study elucidating this relationship among burn victims, several other PTSD studies corroborate our result. For instance, in a review of risk factors for PTSD in general population, Halligan et al described low education level as a prominent demographic risk factor. ${ }^{13}$ Similarly, low education was also found to be associated with greater PTSD by Engelhard, et al." This relation predictably extends to PTSD among burn victims in our study. Lower educational attainment may be a sign of lower IQ and a vast body of research relates lower IQ to higher incidence of various psychiatric disorders. ${ }^{22}$

Another factor, suggested in this investigation is that lower education level may be associated with greater overall stress in life and therefore, a greater risk for psychiatric morbidity. ${ }^{18}$ Finally, those with higher educational accomplishment are more likely to have a positive attitude towards mental health services and are more likely to seek professional help as compared to those with lower education. Higher levels of PTSD was reported among unemployed and housewives. Unemployment has been strongly associated with increasing severity of PTSD symptoms in general population. ${ }^{28}$ However, among burn victims, special factors may contribute to the negative impact of employment on PTSD symptoms. First is the stigmatization of work-colleagues towards employed burn victims which may contribute to increased stress in the latter. Secondly, the increased stress of the work itself when combined with the stress of the recent trauma may be responsible for higher PTSD among working burn victims.

Punjabis, natives of the province where the study was conducted, had higher PTSD than those belonging to other communities. Several studies have found higher levels of PTSD among ethnic minorities as compared to the ethnic majority and these contradict our result. For instance, in a review of PTSD among military veterans, Loo concluded that veterans belonging to ethnic minorities (African-American and Hispanics) generally had higher PTSD than those belonging to the ethnic majority (whites). ${ }^{29}$ It is probable that while PTSD symptoms may be bearable at low levels, when they cross a certain threshold, the sufferer may view suicide as the only means of escape from the bitter reminders of the traumatic event that appear constantly in the form of PTSD symptoms. Screening burn victims for high levels of PTSD and suicidal ideation may be effective in reducing suicides among them.

\section{LIMITATIONS}

There are certain limitations to be considered. The results of this study should be interpreted with caution. The 
cross-sectional design of this study limits inferences about temporality and causality of the results. Use of interviewer based and self-report instruments psychological instruments add potential recall bias, which can be minimized by using ICD-I I or DSM-V criteria for diagnoses of PTSD in future studies. The present study utilized purposive sampling technique. The limited sample size taken from limited units may undermine its generalization.

\section{CONCLUSION}

Among burn victims, several specific factors may contribute to exacerbate PTSD symptoms.

Being male, married, illiterate, urban background, having history of domestic abuse, unemployed/housewives, having lower education level and experienced burn injuries less than one-year duration are significant psychosocial correlates of PTSD in patients with fire burns. Hence this is implied that gaining insight into psychosocial predictors of PTSD in fire burns patients can help psychologists and clinicians in devising effective counseling and therapeutic programs. This in return can safeguard the victims of fire burns from ordeals of psychological burdens after the catastrophe.

\section{REFERENCES}

I. World Health Organization. Burns [WWW Document]; 20I4. [Cited on: February 27, 2017]. Available from URL: http://www.who.int /mediacentre/factsheets/fs365/en/

2. Attia AF, Sherif AA, Mandil AM, Massoud MN, Abou-Nazel MW, Arafa MA. Epidemiological and sociocultural study of burn patients in Alexandria, Egypt. East Mediterr Health J 1997;3(3):452-6I.

3. Jaiswal A, Aggarwal H, Solanki P. Epidemiological and socio-cultural study of burn patients in MY Hospital, Indore, India. Indian J Plast Surg 2007;40(2): 1 58-63. DOI:10.4103/0970-0358.33426

4. Kareem T. Girls Set to Fire. The Dawn. 2015 Aug 28;Sect. A:2 (col. 4).

5. Han P. Q\&A: Acid attacks around the world [WWW Document].
CNN Connect World; 2010. Available from URL: http://edition.cnn.com/20I0/WOR LD/asiapcf/0 I/I I/acid.attack.fact/

6. Nasrullah M, Muazzam S. Newspaper reports: a source of surveillance for burns among women in Pakistan. J Public Health (Oxford) 2010 Jun;32(2):245-9. DOI: I0.1093/pubmed/fdp I 02

7. Pakistani Women Human Rights Association. Recent Victims of Inhuman Attacks with Acid [Internet] 20I0. [Cited on: February 27, 2017]. Available from URL: http://www.pakistaniwomen. org/acid_pwhro.html.

8. Gangemi EN, Gregori D, Berchialla P, Zingarelli E, Cairo M, Bollero D, et al. Epidemiology and risk factors for pathologic scarring after burn wounds. Arch. Facial Plast Surg 2008; I0(2):93-102. DOI: 10.100 I/archfaci. 10.2.93

9. Robert R, Meyer W, Bishop S, Rosenberg L, Murphy L, Blakeney P. Disfiguring burn scars and adolescent self-esteem. Burns 1999;25(7):581-5. DOI: 10.1016/S0305-4179(99)00065-0

10. Dyster-Aas J, Kildal M, Willebrand M. Return to work and healthrelated quality of life after burn injury. J Rehabil Med 2007;39(I):49-55. DOI: 10.2340/16501977-0005

II. Tedstone JE, Tarrier N. An investigation of the prevalence of psychological morbidity in burninjured patients. Burns 1997;23(78):550-4.

12. Boeve SAI, Aaron LA, Martin-Herz SP, Peterson A, Cain V, Heimbach $D M$, et al. Sleep disturbance after burn injury. J Burn Care $2002 ; 23(\mathrm{l}): 32-8$. DOI: I $0.1097 / 00004630$ 200201000-00007

13. Maes M, Mylle J, Delmeire L, Altamura C. 2000. Psychiatric morbidity and comorbidity following accidental man-made traumatic events: incidence and risk factors. Eur Arch Psychiatry Clin Neurosci 2000;250(3): I56-62. DOI:I0.1007/s004060070034
14. Cakir U, Terzi R, Abaci F, Aker T. The prevalence of post-traumatic stress disorder in patients with burn injuries, and their quality of life. Int J Psychiatry Clin Pract 2015 Mar; I9(I):56-9. DOI: I0.3109/1365I50I.2014.98I545

15. American Psychiatric Association (APA). Posttraumatic Stress Disorder [WWW Document] 2013. [Cited on: February 26, 2017]. Available from URL: http://www. dsm5.org/Documents/PTSD Fact Sheet.pdf. DOI: I0.3390/ bs7010007.

16. Zoellner LA, Bedard-Gilligan MA, Jun JJ, Marks LH, Garcia NM. The evolving construct of posttraumatic stress disorder (PTSD): DSM-5 criteria changes and legal implications. Psychol Inj Law 20I3;6(4):277-89. DOI: 10.1007/s | 2207-0|3-9|75-6

17. Kilpatrick D, Resnick H, Milanak M. National estimates of exposure to traumatic events and PTSD prevalence using DSM-IV and DSM5 criteria. J Trauma Stress 2013 Oct;26(5):537-47. DOI: 10.1002/jts. 21848 .

18. Lukaschek K, Kruse J, Emeny RT, Lacruz ME, von Eisenhart Rothe A, Ladwig $\mathrm{KH}$. Lifetime traumatic experiences and their impact on PTSD: a general population study. Soc Psychiatry Psychiatr Epidemiol 2013 Apr;48(4):525-32. DOI: 10.1007/s00|27-0|2-0585-7.

19. Van Loey NE, Van Son MJM. Psychopathology and psychological problems in patients with burn scars. Am J Clin Dermatol 2003;4(4):245-72. DOI: I0.2165/ 00 I 2807| -200304040-00004

20. Sadeghi-Bazargani H, Maghsoudi H, Soudmand-Niri M, Ranjbar F, Mashadi-Abdollahi H. Stress disorder and PTSD after burn injuries: a prospective study of predictors of PTSD at Sina Burn Center, Iran. Neuropsychiatr Dis Treat 20II;7:425-9. DOI: I0.2 I47/NDT.S2304I.

2I. Cheng H, Li X, Miao H, Li R. The role of coping behavior in severely burned patients with posttraumatic 
stress disorder. J Neuropsychiatry Clin Neurosci 2015 Summer; 27(3): I88-92. DOI: 10.1176/appi. neuropsych.13110334.

22. Kafi SM, Atashkar SR, AMIR AS, Rezvani S. Relationship of posttraumatic stress disorder with psychological defence styles in burn patients. 2013; 19(3): I55-60.

23. Bosmans MW, Hofland HW, De Jong AE, Van Loey NE. Coping with burns: the role of coping self-efficacy in the recovery from traumatic stress following burn injuries. J Behav Med 2015 Aug;38(4):642-5I. DOI: I0.1007/s 10865-015-9638-I.

24. Ven Loey NE, Maas CJ, Faber AW, Taal LA. Predictors of chronic posttraumatic stress symptoms following burn injury: results of a longitudinal study. J Trauma Stress 2003; I 6(4):36I-9. DOI: I0.1023/A: 1024465902416

25. El Hamaoui Y, Yaalaoui S, Chihabeddine K, Boukind $\mathrm{E}$, Moussaoui D. Post-traumatic stress disorder in burned patients. Burns 2002;28(7):647-50. DOI: 10.1016/S0305-4179(02)00100-6

26. Lawrence JW, Fauerbach JA. Personality, coping, chronic stress, social support and PTSD symptoms among adult burn survivors: a path analysis. J Burn Care Rehabil 2003;24(I):63-72. DOI: 10.1097/ 00004630-20030I000-000I6

27. Xia ZY, Kong Y, Yin TT, Shi SH, Huang R, Cheng $Y H$. The impact of acceptance of disability and psychological resilience on posttraumatic stress disorders in burn patients. Int J Nurs Sci 20 I 4; I (4):37I-75. DOI: $10.1016 / j . j j n s s .2014 .10 .018$

28. Ward HW, Moss RL, Darko DF, Berry CC, Anderson J, Kolman P, et al. Prevalence of postburn depression following burn injury.J Burn Care Rehabil 1987 Jul-Aug; 8(4):294-8.

29. Loo CM. Report on the Asian American Vietnam Veteran RaceRelated Study (AVRS). Honolulu, HI: National Center for PTSD, Pacific Islands Division and Department of Veterans Affairs, VA Pacific Islands Health Care System. 200 I

\section{AUTHOR'S CONTRIBUTION}

Following authors have made substantial contributions to the manuscript as under:

AM: Conception and design; acquisition of data; drafting the manuscript; final approval of the version to be published

FK \& RR: Acquisition, analysis and interpretation of data; drafting the manuscript; final approval of the version to be published

Authors agree to be accountable for all aspects of the work in ensuring that questions related to the accuracy or integrity of any part of the work are appropriately investigated and resolved.

This is an Open Access article distributed under the terms of the Creative Commons Attribution-NonCommercial-NoDerivatives 4.0 International License (https://creativecommons.org/licenses/by-nc-nd/4.0/) which permits to reproduce freely in any medium and share the Licensed Material, for NonCommercial purposes only, provided the original work is properly cited. 